\title{
Modelling of clustered distributed generation for economic requirements
}

\author{
M. Neubert, G. Balzer \\ Institute of Electrical Power Systems \\ TU-Darmstadt \\ Landgraf-Georg-Straße 4 \\ 64283 Darmstadt \\ Phone number: +49 6151 16-5452, +49 6151 16-4852 \\ e-mail: marc.neubert@eev.tu-darmstadt.de, gerd.balzer@eev.tu-darmstadt.de
}

\begin{abstract}
In this paper, economical and technical considerations of distributed generation units (DGU) will be presented in two steps. The first one analyses economic side of the distributed generation units. The calculation of total cost as well as the specific generation cost will be presented. The last newly defined parameter allows to compare different distributed generation units with their own and with traditional thermal power plants. In the second step, the technical restrictions like power stability or load flow will be considered. To do this, the model of a low voltage (LV) network has been created. The network has been divided into cluster, where DGU and loads are included. The DGU will be driven in two operating modes: firstly variable load according to the load curve and secondly with full load. Bringing these two models together the following conclusion will be drawn. The use of distributed generation units cannot be considered only from the technical point of view. The economic view plays also an important role.
\end{abstract}

\section{Key words}

distributed generation, economic structure, specific generation cost, low voltage network

\section{Introduction}

The decreed of the renewable energy law and the law for expanding of combined heat and power production created in Germany a fast growing energy market for distributed generation. Its liberalization forces structural changes in Europe. Therefore, its economic analysis, explicitly reduction of specific generation cost plays a major role in the power supply. Additionally, the margin of benefits decreases constantly and that is why the power supplier has to find a way to optimize cost. It has also to be mentioned, that the technical limits and the traditional vertical power flow are also no longer guaranteed. The main distributed generation units (DGU), which are subsidised by these laws, are wind farms, micro turbines, stirling engines, fuel cells and cogen- eration units. In order to face up these changes new requirements have to be formulated. This formulation process can be done in two steps. The first one analyses the economic structure of DGU in order to define profitability in comparison to the traditional power plants. The comparison can be done with use of specific generation cost. The second step considers the technical limits of the network with DGU. This can be done with use of clustered distributed generation.

\section{Economic structure of distributed generation units}

The analysis of the economy of distributed generation units in the power supply is basically new. Comparability and power scheduling is no longer restricted to great thermal power plants and distributed generation will play an important role in this case. To receive more information about the economic structure, the research of the total cost $K_{\text {total }}$ will be presented. A general formulation of the total cost can be generally written in form of Equation 1:

$$
K_{\text {total }}=K_{\text {fixed }}+K_{\text {variable }}(x)
$$

The categorisation into two groups can be justified thereby, that the fixed cost $K_{\text {fixed }}$ consist only of the acquisition and enterprise and are independent of the operating method and time. The second part consist of the variable cost $K_{\text {variable. The common }}$ parameters like time, intensity of use or abrasion have to be counted. These are represented by the variable $x$.

A precise classification of the total cost is presented in Table 1. Both groups of costs can be subdivided. The first group belongs to the fixed costs. The investment cost and depreciation have great influence on the capital costs. Tariff rates and administrative fees are contained in the auxiliary cost and have only small importance to the fixed costs. The second group describes the components of the variable 
costs. With regard to the parameters of operating costs, these are often included in a full service contract by a DGU manufacturer as well as auxiliary means but without start-up cost. This kind of contracting assigns the responsibility of warranty and maintenance to the manufacturer for the live time use. For the start-up cost, it is necessary to know the DGU parameters very precisely in order to get a satisfied result. At least in the group of consumption costs is embedded the parameter fuel. This cost has the most influence on the variable costs and depends on parameters like efficiency and operating method.

Table 1 Classification of total cost

\begin{tabular}{|c|c|c|}
\hline \multirow[t]{2}{*}{$\begin{array}{l}\text { Fixed } \\
\text { costs }\end{array}$} & $\begin{array}{l}\text { Capital } \\
\text { costs }\end{array}$ & $\begin{array}{l}\text { Investment cost } \\
\text { Depreciation } \\
\text { Building charges } \\
\text { Rental fee }\end{array}$ \\
\hline & $\begin{array}{l}\text { Auxiliary } \\
\text { costs }\end{array}$ & $\begin{array}{l}\text { Tariff rates } \\
\text { Administrative fees } \\
\text { Insurance cost }\end{array}$ \\
\hline \multirow[t]{2}{*}{$\begin{array}{l}\text { Variable } \\
\text { costs }\end{array}$} & $\begin{array}{l}\text { Operating } \\
\text { costs }\end{array}$ & $\begin{array}{l}\text { Maintenance cost } \\
\text { Start-up cost } \\
\text { Personal cost }\end{array}$ \\
\hline & $\begin{array}{l}\text { Consumption } \\
\text { costs }\end{array}$ & $\begin{array}{l}\text { Fuel cost } \\
\text { Auxiliary means }\end{array}$ \\
\hline
\end{tabular}

The further consideration will be done according to the schema already presented in the Table 1 . The detail equations will be established for the technical and economical behaviour of the DGU.

\section{A. Fixed costs}

Fixed costs in literature are defined as: "In general, cost that does not change with changes in the quantity of output produced. More specifically, fixed cost is combined with the adjectives total and average to indicate the overall level of fixed cost or the per unit fixed cost. Fixed cost is incurred whether of not any output is produced. The same fixed cost is incurred at any and all output levels [1]."

The investment cost compose in most cases the greatest part of the fixed costs. Investment are usually long time running funds. The emphasis is often to be laid on the decision of acquisition. Two different approaches for the calculation of investments are given in the literature. In the dynamic method the time for transfers of in- and outcomings are included. In contrast to this, the parameters of transfers are used as mean values for the static method, which needed an exact forecast. To make the different power plants comparable it is reasonable to finance the complete plant by a credit. The capital costs $K_{C}$ consist of the investment cost and the rate of interest $i$, which can be annualised in constant amounts $K_{\mathrm{A}}$ by the annuity method. A linear depreciation $K_{\mathrm{LD}}$ is used, whereas the residual book value $R V$ at the asset depreciation range $n$ is zero. Equation 2 clarifies the statements above:

$$
\begin{aligned}
K_{\mathrm{C}} & =K_{\mathrm{A}}+K_{\mathrm{LD}} \\
& =A_{0} \cdot \frac{i(1+i)^{n}}{(1+i)^{n}-1}+\frac{A_{0}-R V}{n}
\end{aligned}
$$

The parameters of the auxiliary costs plays only a minor role. They do not constitute $1 \%$ of the entire cost. Furthermore, the complete auxiliary costs is for different DGU quite similar and therefor for this work negligible.

\section{B. Variable costs}

In comparison, the variable costs is defined as:" A cost that is dependent on quantity of output. That varies in proportion to the quantity produced and is incurred as a direct result of operation of the business. Theoretically, variable costs are zero if there is no production. As opposed to fixed cost [1]."

The operating costs normally consist of the parameters like maintenance, start-up and personal cost. Generally, these cost are without any production not zero. However, most of DGU manufacturers provide a full service contracting, where the following partial cost are included. These costs are maintenance cost, personal cost and auxiliary means. During none operation the cost can be reduced to zero. A ideal case of cost reduction to zero gives customer the lowest costs that can be achieved. Any other amount seems to result in a higher costs, which has to be paid. From this results the function of the maintenance cost $K_{m}$ for a full service contract:

$$
K_{m}=P_{e l} \cdot t \cdot k_{m}
$$

On the one hand, the constant value of specific maintenance cost $k_{m}$ is responsible for the growth, which is negotiated between the contractor and the owner of the DGU. Here, exist the risk of an eventually high personally negotiated contract for the specific maintenance cost that let the cost even more increase. On the other hand the electrical energy as a function of the running time $t$ and the electrical power output $P_{e l}$ takes responsibility for the cost during operation. Hence, a three dimensional space of maintenance cost can be calculated.

Additionally, to the parameters mentioned above, the value of the start-up cost $K_{s u}$ has to be taken into account. The formulation is given in Equation 4:

$$
K_{s u}=K_{0}+\gamma \cdot\left(1-e^{-\frac{t}{\tau}}\right)
$$


The value that must be at least payed at the beginning of the start-up is represented by $K_{0}$. This variable describes one of the costs, the heat requirement during starting up of an engine or the cost of stand still during an outage. From that point, the function has an asymptotic behaviour up to the maximum of the consumption costs, which is limited through the rated power output represented by the factor $\gamma$. This parameter is only constrained by the fuel demand of the DGU. The starting up period depends on the DGU time constant $\tau$, which differs between $\mathrm{DGU}^{\prime} \mathrm{s}$ in a range from seconds up to minutes.

At least the fuel cost $K_{\text {fuel }}$ must be discussed, which has the most influence on the variable costs and on the economics. The dependencies are represented by equation:

$$
K_{\text {fuel }}=P_{\text {el }}(\eta) \cdot t \cdot k_{\text {fuel }}
$$

For the calculation purpose it is assumed, that only the required fuel price $k_{f u e l}$ is constant. An other possibility would be a piecewise constant price function for the fuel requirement. The electrical output depends on the efficiency $\eta$ and therefore on the fuel insert, which is needed to get the required power output. Two variants are traditional for the consideration of the fuel insert. First, the linear and as second the exponential approach. Both possibilities are expressed in the equations below:

$$
\begin{aligned}
\text { fuel }_{\text {insert }} & =a+b \cdot P_{\mathrm{el}} \\
\text { fuel }_{\text {insert }} & =a+b \cdot P_{\mathrm{el}}+c \cdot P_{\mathrm{el}}^{2}
\end{aligned}
$$

For further calculation of the fuel cost some boundary conditions have to be considered, i.e. the range of the part load and its behaviour. According to this, a suitable fuel insert Equation 6 or 7 has to be chosen for the calculation of the variable cost. In case of no suitability, a modification can be undertaken like piecewise linearisation of the fuel insert curve, with a stepwise refinement of the regarded interval.The relationship of power output to fuel insert is in small power plants, similar to the regarded DGU in a great range of the part load a nearly linear function [2]. Great thermal power plants have instead generally an exponential ratio [3].

\section{Total and specific generation cost}

By the reflection of the theoretical established equations, the total cost can be completed as followed:

$$
\begin{aligned}
K_{\text {total }} & =K_{\text {fixed }}+K_{\text {variable }}(x) \\
& =K_{C}+K_{m}+K_{s u}+K_{\text {fuel }}
\end{aligned}
$$

The total cost consist of the presented parts of the fixed and variable costs and can be consulted for any calculation of cost for distributed generation units. The interest of any DGU lies in the calculation of the specific generation cost $k_{\text {specific }}$ on hand of already calculated price structure. Hence the economic merit order chart represents the price structure of power plants depending on the running time and the specific generation cost. In this case, the specific generation cost is represented as ratio of the total generated energy $E_{\text {total }}$ and the variable cost $K_{\text {variable: }}$

$$
k_{\text {specific }}=\frac{E_{\text {total }}}{K_{\text {variable }}}
$$

The power supply is normally orientated to the generation schedule and dispatched according to the desired merit order. Dispatching power is to be set, in merit order of generation from lowest to the highest marginal cost output necessary to meet demand. The consequence is, that power is supplied at the minimum cost, at each point of time and as demand increases, more expensive plants are brought on line. The theory of deregulation is, of course, that the pressure of competition will force generation to minimise their cost in order to maximise the profits [4]. The result, received from Equation 9, allows in addition to the established price structure and to its price settings the comparison of different DGU.

\section{Numerical consideration and com- parison}

In this section the analyse of the established price structure on the basis of a numerical consideration of a DGU will be presented. The proceeding will be the same as in the section before. The main regard will be laid on the variable cost, which is responsible for specific generation cost and the power scheduling. The fixed cost can be very useful in acquisition of any DGU. A comparison of the specific generation cost of great thermal power plants to distributed generation units will finally be presented. An example of price structure for a microturbine from manufacturer Capstone including technical and economical parameters is listed in Table 2.

Table 2 Parameters of a microturbine

\begin{tabular}{|l|l|}
\hline$P_{\mathrm{r}}$ & $30 \mathrm{~kW}$ \\
\hline Part load & non linear between \\
behaviour & $0,5 \cdot P_{\mathrm{r} \text { el }}$ to $P_{\mathrm{r} \text { el }}$ \\
\hline Investment cost & $50.000 €$ \\
\hline Maintenance cost & $0,28 € / \mathrm{kWh}$ \\
\hline Time of depreciation & 10 years \\
\hline Fuel price & $0,026 € / \mathrm{kWh}$ \\
\hline Rate of interest & $6,5 \%$ \\
\hline
\end{tabular}


The described data should not be assessed, whether this DGU is a proportionally expensive or favorable one. The values are typical for a $30 \mathrm{~kW}$ power plant. The manufacturer indicates the investment cost as $50.000 €$ and in a full service contract the specific maintenance cost $k_{m}$ are itemised with amount of $0,28 € / \mathrm{kWh}$. Additionally, for the calculation purpose, the time of depreciation has been chosen equal to 10 years, according to recommendation [5]. Typical fuel price, in case of low pressure gas connection to the power plant amounts $0,026 € / \mathrm{kWh}$. For a financing by the bank, the value of interest rate is prescribed to $6,5 \%$. Unfortunately, parameters for the start-up are only reserved for manufacturer and owner of DGU. Therefore, they will be neglected in calculations.

\section{A. Variable cost}

According to the succession of the variable costs in Table 2 the first point, which has to be calculated is a full service contract. At Figure 1, the three dimensional space of the maintenance cost, which is defined in Equation 3, is presented below.

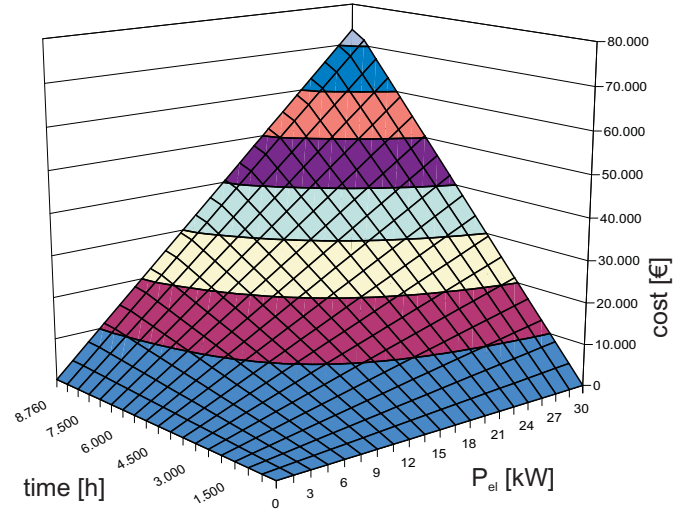

Fig. 1 Maintenance cost

The $\mathrm{x}$-axis shows the power output from 0 up to $30 \mathrm{~kW}$, according to the power output of the microturbine given in Table 2. On the $\mathrm{y}$-axis the running time is displayed in hours for a whole year. The z-axis represents the maintenance cost, which results from the running time and the power output. Generally, for better comparability of different DGU, the axis notations should be scaled to these parameters. It can be seen, that the maintenance cost appears like a part of a cone, because of the linear dependencies of time and power output. Only the gradient, which depends on the specific maintenance cost $k_{m}$ is responsible for the difference between various full service contracting. From Figure 1, it is possible to locate any appropriate maintenance cost depending on these two parameters.

The next step consist of the calculation of the fuel cost. The economical and machine parameters differs extremely between various DGU. The manufacturer govern data like efficiency, combustion input and temperature conditions. In Figure 2 the partload behaviour of the microturbine as the ratio of efficiency to electrical power output at ISO conditions is given.

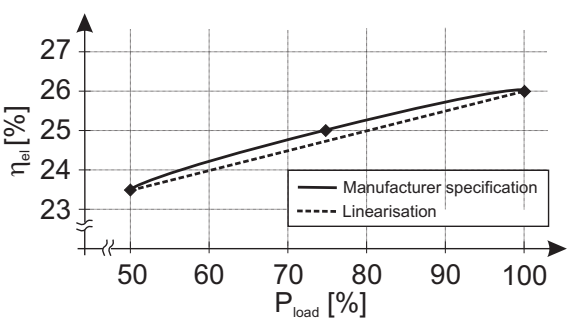

Fig. 2 Part-load behaviour [2]

The solid line represents the data of the manufacturer. At maximum of electrical power output, the microturbine has an efficiency of $26 \%$. The reduction of electrical power down to $50 \%$ causes only small decreasing of the efficiency to $23,5 \%$. The third data point is given, where the electrical power equals to $75 \%$ and efficency to $25 \%$. These points illustrate the non linear behaviour of the microturbine. For the calculation purposes the part-load characteristic, has been linearised and is to be seen as the dashed line. The maximal difference between those two curves occures at the middle data point and amounts $0,25 \%$. This kind of linearisation has negligible influence on the final result. The fuel cost is calculated as function of Equations 5 and 6 , of the linearised part-load behaviour and is presented in Figure 3. The axis notations and parameters meaning are the same like for maintenance cost. It can be recognised that for example along the $15.000 €$ level, the power is not constant. It increases slightly

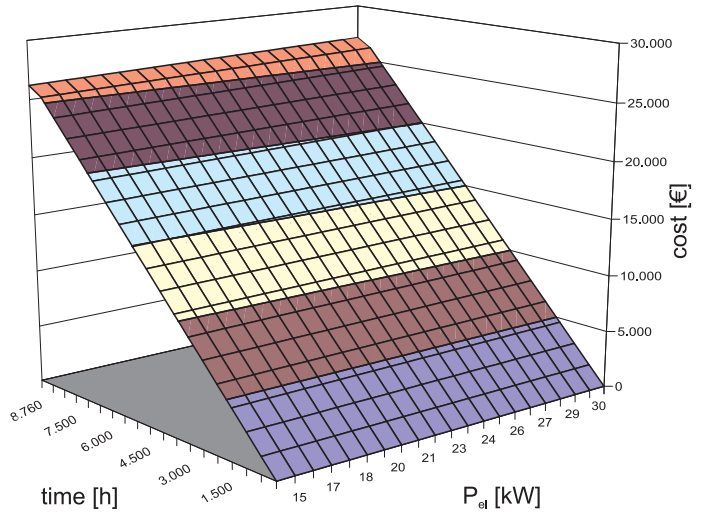

Fig. 3 Fuel cost 
by simultaneously power increase. Such behaviour is a consequence of the part-load behaviour of the DGU given in Figure 2. Therefore, the fuel cost increases constantly with the running time along its axis.

As the last one, the calculation of the variable cost $K_{\text {variable, without the start-up cost will be pre- }}$ sented. The complete equation can be formulated as:

$$
K_{\text {variable }}=K_{\text {fuel }}+K_{m}
$$

The sum of the two partial cost gives the variable costs, which can also be presented in the three dimensional space.

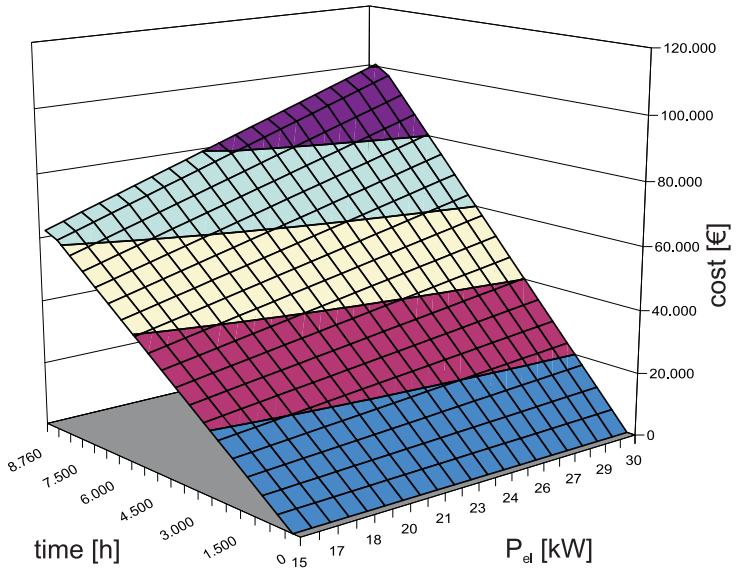

Fig. 4 Variable costs

As Figure 4 illustrates, it is reasonable to limit the range of the electrical power output to the operating range of the DGU. The result space is an inclined plane, which increases more with the maintenance cost than to the fuel cost. Additionally, Figure 4 is comparable to other generation units and gives the possibility to define any variable costs during operation. According to the total cost, the fixed cost $K_{C}$ can be taken into account. This means, that in Figure 4, the annual cost would cause an offset, up to the amount which is calculated through Equation 2.

\section{B. Specific generation cost calculation}

The specific generation cost $k_{\text {specific }}$ have already been presented in Equation 9. Considering the variable costs, the start-up cost can be neglected as already mentioned. The modified Equation 11 is given below:

$$
\begin{aligned}
k_{\text {specific }} & =\frac{E_{\text {total }}}{K_{\text {fuel }}+K_{m}} \\
& =\frac{P_{\mathrm{el}}}{P_{\mathrm{el}}(\eta) \cdot k_{\text {fuel }}+P_{\mathrm{el}} \cdot k_{m}}
\end{aligned}
$$

For clarifying the dependencies on the variable costs, Figure 5 is given.

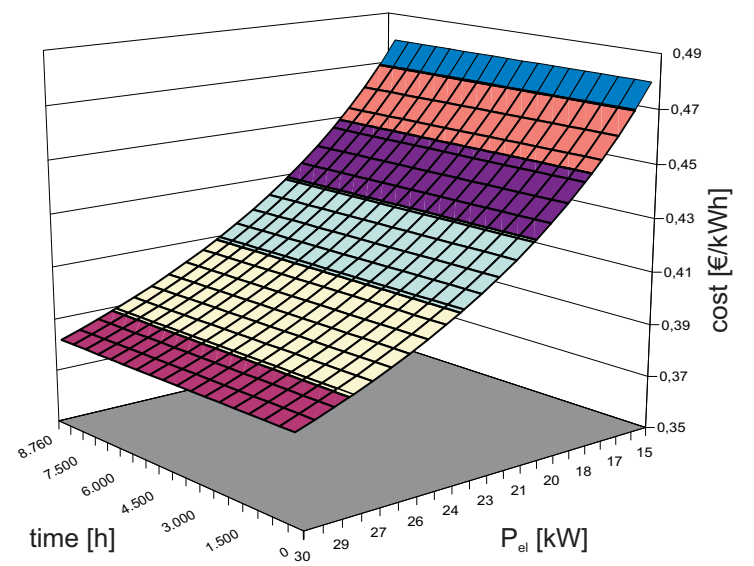

Fig. 5 Specific generation cost

The notation of the presented Figure 5 differs from the others, because the scaling along the electrical power is in reverse order to get a satisfied figure. Regarding to the specific generation cost, the curve decreases with simultaneous increase of the electrical power. Additionally, along the running time the specific cost is constant. Each parameter in Equation 11 depends on time. For this reason the time factor can be removed and then the specific cost will not depend on time. This case is only correct under the mentioned conditions otherwise the time has to be taken into account. Consequential, the parameters with influence in this Equation are, the electrical power $P_{\mathrm{el}}(\eta)$, as well as the specific maintenance cost $k_{m}$ and the fuel price $k_{\text {fuel }}$. It can be said, that the operating mode has to be orientated by the power demand and not by the utilisation. The definition of base or peak load could not be used as long as the power generation reaches maximum and therefore at lowest specific generation cost.

Finally, the specific generation cost of the DGU can be compared with a traditional thermal power plant. A general block size has an amount of $400 \mathrm{~kW}$ and an average efficiency of $\eta=55 \%$. The calculated specific generation cost, whithout transmission and distributed network equals to $2,9 \mathrm{Cent} / \mathrm{kWh}$. Taking into account the transmission and the power losses the price increases up to 12,5 Cent/ $\mathrm{kWh}[6]$. The lowest generation cost of the DGU that has been achieved equals to $38 \mathrm{Cent} / \mathrm{kWh}$, which is much higher than for the thermal power plant. Under special circumstances these cost can be reduced by taking advantage of the law for expanding of combined heat and power with $5,11 \mathrm{Cent} / \mathrm{kWh}$. At least by using biogas as fuel, the renewable energy law can also be utilised. 


\section{Technical considerations of clus- tered distributed generation}

The structural network changes occur very slowly in the liberalised energy market and especially in the LV-Network. In this case, it is important firstly to analyse the actual network structure and secondly the network extension as a future scenario for DGU. The VDN has established a homogeneous radial low voltage network, which is based on structure characteristics like population density $\left[\mathrm{EW} / \mathrm{km}^{2}\right]$, demand density $\left[\mathrm{MWh} / \mathrm{km}^{2}\right]$ and wiring level [7]. This will be the basis of the technical research. The modification in this network will be done by connecting the DGU to the busbar. Thereby, the influences of the distributed generation on the network will be analysed.

\section{A. Clustered LV-network model}

The established model shall contribute to analyse existing and new network structures in coherence with distributed generation. Different possibilities of feeding and demand can be considered in the model. The VDN-network will be modified into a clustered LV-network, which consists on actual network structure and connected DGU. The clustered model can be separated into several clusters, which can be connected serial and parallel. New structures of the LV-network can be created and analysed with this approach. An example of cluster with distributed generation is given on Figure 6 .

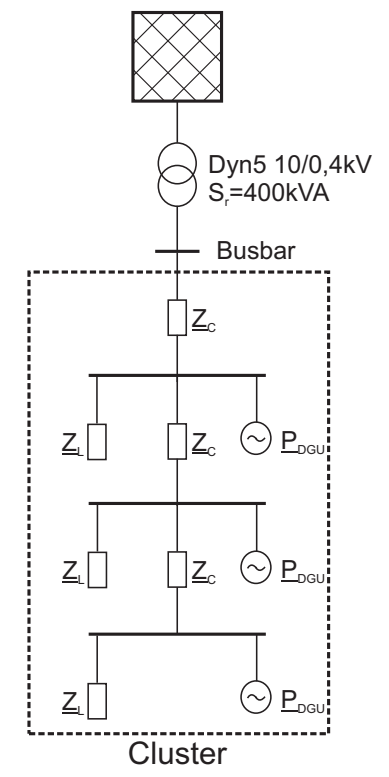

Fig. 6 Clustered distributed generation

The power is supplied by a middle voltage substation with $S_{k \max }^{\prime \prime}=250 \mathrm{MVA}$ and is connected to a power transformer with $S_{r}=400 \mathrm{kVA}$. The cluster itself consists of three loads given as constant
Impedance $\underline{Z}_{L}$ each, which represents the household loads. Additionally, the DGU are connected to each busbar of the households and represent the distributed power supply of the households. The power ratio between DGU and loads within the considered cluster can vary between:

$$
P_{D G U}=\left\{\begin{array}{l}
0 \\
\frac{1}{3} \cdot P_{\text {load }} \\
\frac{2}{3} \cdot P_{\text {load }} \\
P_{\text {load }}
\end{array}\right.
$$

With higher appearance of DGU and thereby a higher feeder ratio, different cluster behaviour can be analysed. Regarding the technical limits, maximum cable capacity, power transformer capacity and requirements to the maximum voltage drop can be generally identified in clustered distributed generation. In order to define the limits for named restrictions, the different serial and parallel connections of clusters were tested.

\section{B. Technical limits in serial clustered distributed generation}

The clustering extension problem is restricted to different parameters. The technical limits of the devices have to be regarded as well as retroactive effects on the network. Serial connected clusters represent traditional network structures and is shown on Figure 7.

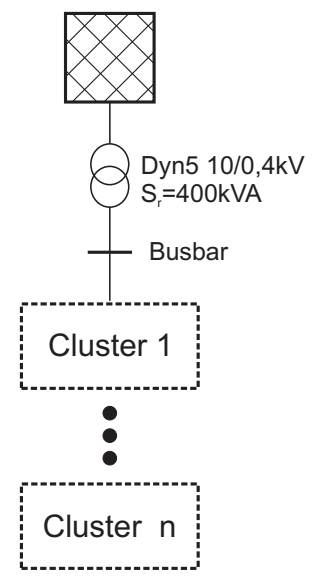

Fig. 7 Serial clustered distributed generation

The maximum cable capacity and the maximum voltage drop at the busbar are responsible for the restriction in serial clustered distributed generation. The maximum current, which can be transported by the cable, is much lower in comparison to the power transformer. In serial cases, the limitation of the power transformer can be neglected. Under the given conditions the results of the simulations can be summarised in Table 3 . 
Table 3 Technical limits in serial clustered network

\begin{tabular}{|c|c|c|c|c|}
\hline $\begin{array}{c}\text { Simu- } \\
\text { lation }\end{array}$ & $\begin{array}{c}\text { Ratio } \\
\frac{P_{D G U}}{P_{\text {load }}}\end{array}$ & $\begin{array}{c}\text { Operation } \\
\text { mode }\end{array}$ & Limitation & $\begin{array}{c}\text { No. of } \\
\text { cluster }\end{array}$ \\
\hline \hline 1 & none & none & Cable & 2 \\
\hline 2 & $1 / 3$ & load curve & Voltage drop & 2 \\
\hline 3 & $1 / 3$ & full load & Voltage drop & 2 \\
\hline 4 & $2 / 3$ & load curve & Voltage drop & 3 \\
\hline 5 & $2 / 3$ & full load & Over Voltage & 3 \\
\hline 6 & $3 / 3$ & load curve & Voltage drop & 3 \\
\hline 7 & $3 / 3$ & full load & Over Voltage & 2 \\
\hline
\end{tabular}

The reference case is simulation 1 , where the traditional LV-network structure without DGU is considered. This network can operate without limitations if there are only two serial connected clusters. Connecting the third one, the maximum capacity of cable nearest to busbar will be exceeded. An extension of DGU could solve the problem. In following it is considered, what number of cluster could be achieved be given power ratio of demand to DGU. The power ratio will be increased in 3 steps according to Equation 12. Thereby, the operation mode of the DGU will be changed between full load and variable load following the day load curve. Considering the part-load behaviour, the DGU will only operate if the power demand of the household is in range of the part-load of the DGU. From this follows, that the DGU will be turned-off during the night and turned-on during the day operating at variable load.

Increasing the power ratio to $1 / 3$, the number of allowed cluster connections can not be increased. This is caused by the insufficient power supply of the DGU and by the voltage drop, which lies beyond the prescribed parameters. However, the DGU is a supplement to the traditional power supply and reduces losses in the network.

In simulation 4 and 5 , the extension is possible. Because of the increase of installed power of the DGU, the third cluster can be connected to the network. Additionally the voltage drop can be reduced. The limiting factor in simulation 5 , where over voltage appeared during the night, is that the demand has decreased while the DGU was still operating at full load.

An additional expand of power ratio in simulation case 6 does not effect any change in the number of serial cluster. The reason of this stagnation is caused by the time, where the DGU will be turnedon. The demand of the households has increased during night up to the limitation of cable capacity. At this time the DGU are still turned-off and can not support the power supply.

In simulation 7 the number of cluster decreased to two. The over voltage in the cluster during night appeared because of the same reasons like in simulation 5 but in this case the limits has been reached earlier because of the increased supply of the DGU.

\section{Technical limits in parallel clustered distributed generation}

With research of parallel clustered distributed generation new network structures can be created. The parameters of the network and the procedure of identifying the technical limits remains the same as in previous simulation. In Figure 8 the general structure of parallel clustering is given.

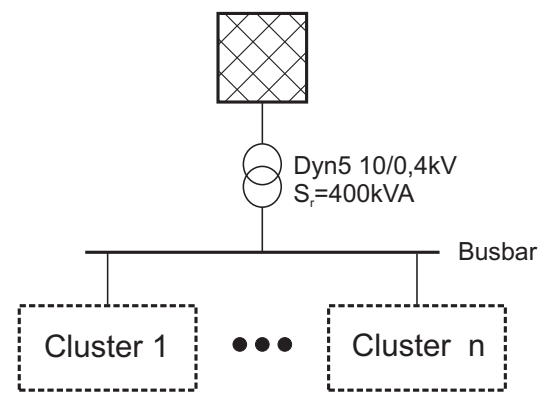

Fig. 8 Parallel clustered distributed generation

For the first analysis of parallel clustering, only one cluster will be connected in serial to the busbar. Following this, the restriction to maximum current in the cable can be neglected, because it will never be reached. The power transformer and the voltage drop at the busbar are the only limitations. The results of the simulations are summarised in Table 4 .

Table 4 Technical limits in parallel clustered network

\begin{tabular}{|c|c|c|c|c|}
\hline $\begin{array}{l}\text { Simu- } \\
\text { lation }\end{array}$ & $\begin{array}{l}\text { Ratio } \\
\frac{P_{D G U}}{P_{\text {load }}}\end{array}$ & $\begin{array}{c}\text { Operation } \\
\text { mode }\end{array}$ & $\begin{array}{c}\text { Limita- } \\
\text { tion }\end{array}$ & $\begin{array}{l}\text { No. of } \\
\text { cluster }\end{array}$ \\
\hline 1 & none & none & \multirow{7}{*}{$\begin{array}{c}\text { over } \\
\text { load of } \\
\text { power } \\
\text { trans- } \\
\text { former }\end{array}$} & 4 \\
\hline 2 & $1 / 3$ & load curve & & 5 \\
\hline 3 & $1 / 3$ & full load & & 6 \\
\hline 4 & $2 / 3$ & load curve & & 8 \\
\hline 5 & $2 / 3$ & full load & & 9 \\
\hline 6 & $3 / 3$ & load curve & & 8 \\
\hline 7 & $3 / 3$ & full load & & 5 \\
\hline
\end{tabular}

The parallel connection of cluster solves problems with new network structures. The limitation of this network are connected with the maximum power, that can be supplied by the transformer. It is obvious that an increase of distributed generation will also increase the amount of available power and therefore the number of cluster connected to the busbar can be increased. This result can be seen in Table 4 for simulation cases 1 to 6 .

Excepting simulation 6 has no additional increase in cluster by increasing the distributed generation. 
This has the same reasons like in simulation 6 of serial clustering caused by the time where the DGU will be turned-on.

Also in simulation 7 a decrease of cluster can be registered. The limitation of the transformer are reached earlier because of power decrease during night, while the DGU operates on full load, like in simulation 7 of serial clustering.

As result of these simulations can be followed, that an increase of distributed generation not consequently result in a simultaneous increase in the number of cluster, as seen in the serial clustering. While the limit of feeding ratio is $1 / 3$, there is only little change registered. With higher feeding ratio the regard of operational mode claims to the fore. In full load mode, the restrictions are harmed by power reclamation during following the load curve the power demand is responsible to it. Consolidate the restrictions DGU have to adjust to each other which follows that DGU has not to be orientated by each single household, but in regard to the load curve of the whole LV-network. This stood in economic contrast to the owner of the DGU. From sight of the owner, their maximum return results in maximum power supply to LV-network. The technical benefit will result by a decentralised power scheduling with the number of DGU in a virtual power plant.

\section{Conclusion}

Considering distributed generation not only the wind farms connected to high voltage network have to be taken into account but also distributed generation units like micro turbines or combustion engines connected to the low voltage network. In order to face up these changes, the new requirements have to be formulated. This formulation process can be done in two steps. The first one analyses the economic structure of DGU in order to define profitability in comparison to the traditional power plants. The comparison can be done with use of specific generation cost. The second step considers the technical limits of the network with DGU. The analyse of those two models leads to the conclusion that, as long as the network limits are not exceeded the distributed generation unit has to be orientated on the maximum economic optimum.

\section{References}

[1] Amos Web Encyclonomic WEB*pedia, www.amosweb.com

[2] Hessen Energie Gesellschaft für rationelle Energienutzung mbH, Mikrogasturbine im Markt der Kraft-Wärme-Kopplungsanlagen, 07.2004
[3] H. Wolter, Kurzfristige Kraftwerkseinsatzplanung in thermischen Systemen mit langfristigen Nebenbedingungen, Diss. 1990

[4] A.E. Kahn, Pricing in the Carlifornia Power Exchange Electricity Market, Blue Ribbon Panel Report, 2001

[5] R. Schiefer, Amtliche Afa-Tabellen, IdwVerlag, Düsseldorf

[6] M. Brockmann, Wirtschaftlichkeitsanalyse im Vergleich der traditionellen mit der dezentralen Gebäudeenergieversorgung,VDEKongress Berlin, 2004

[7] J. Karzfey et al, Modellnetzverfahren zur Bestimmung kostentreibender Strukturmerkmale, EW-Magazin, März 200 